\title{
Factors influencing transfection efficiency of pIDUA/nanoemulsion complexes in a mucopolysaccharidosis type I murine model
}

This article was published in the following Dove Press journal:

International Journal of Nanomedicine

15 March 2017

Number of times this article has been viewed

\author{
Michelle Fraga ${ }^{1,2}$ \\ Talita Giacomet de \\ Carvalho ${ }^{2,3}$ \\ Juliana Bidone' \\ Roselena Silvestri Schuh ${ }^{1,2}$ \\ Ursula Matte ${ }^{2,3}$ \\ Helder Ferreira Teixeira' \\ 'Pharmaceutical Sciences Graduate \\ Program, Universidade Federal do Rio \\ Grande do Sul, ${ }^{2}$ Gene Therapy Center, \\ Experimental Research Center, \\ Hospital de Clínicas de Porto Alegre, \\ ${ }^{3}$ Genetics and Molecular Biology \\ Graduate Program, Universidade \\ Federal do Rio Grande do Sul, \\ Porto Alegre, Brazil
}

\begin{abstract}
Mucopolysaccharidosis type I (MPS I) is an autosomal disease caused by alpha-L-iduronidase (IDUA) deficiency. This study used IDUA knockout mice as a model to evaluate whether parameters such as dose of plasmid and time of treatment could influence the transfection efficiency of complexes formed with PEGylated cationic nanoemulsions and plasmid (pIDUA), which contains the gene that encodes for IDUA. Formulations were composed of medium chain triglycerides, 1,2-dioleoyl-sn-glycero-3-phosphoethanolamine, 1,2-distearoyl$s n$-glycero-3-phosphoethanolamine- $N$-(amino[polyethylene glycol]-2000), 1,2-dioleoyl-snglycero-3-trimethylammonium propane (DOTAP), glycerol, and water and were prepared by the adsorption or encapsulation of preformed pIDUA-DOTAP complexes by high-pressure homogenization. A progressive increase in IDUA expression was observed with an increase in the dose and time of transfection for mice treated with both complexes (adsorbed and encapsulated), especially in the liver. Regardless of the complex administered, a significant increase in IDUA activity was detected in lungs and liver compared with nontreated MPS I when a dose of $60 \mu \mathrm{g}$ was administered and IDUA activity was measured 7 days postadministration. Tissue sections of major organs showed no presence of cell necrosis, inflammatory infiltrate, or an increase in apoptosis. Furthermore, immunohistochemistry for CD68 showed no difference in the number of macrophage cells in treated and nontreated animals, indicating the absence of inflammatory reaction caused by the treatment. The data set obtained in this study allowed establishing that factors such as dose and time can influence transfection efficiency in different degrees and that these complexes did not lead to any lethal effect in the MPS I murine model used.
\end{abstract}

Keywords: cationic nanoemulsions, DSPE-PEG, MPS I, plasmid, pIDUA

\section{Introduction}

Gene therapy has emerged as a promising strategy for a wide range of inherited and acquired diseases. ${ }^{1}$ For successful gene therapy, genes have to be delivered to the nucleus of target cells in a safe and effective manner. In the past few decades, a number of viral and nonviral carriers that can be used to transfer foreign genetic material into cells have been developed aimed at enhancing gene transfer in vitro and in vivo.,3 Viral vectors have been widely used to achieve efficient gene transfer. However, issues related to safety, risk of insertional mutagenesis, and the strong immune response generated by these vectors have limited their application. ${ }^{1}$

Nonviral gene carriers have been extensively investigated as alternatives to viral vectors for gene delivery since they offer considerable advantages such as safety and easy production. ${ }^{3,4}$ Cationic nanoemulsions have been considered as potential nonviral nucleic acid delivery systems. ${ }^{5}$ We recently described the design of PEGylated cationic
Teixeira

Faculdade de Farmácia, Universidade

Federal do Rio Grande do Sul, Avenida Ipiranga, 2752, 90610-000 Porto

Alegre, Brazil

Tel +555133085090

Fax +55 5I 33085437

Email helder.teixeira@ufrgs.br 
nanoemulsions as a delivery system for a plasmid containing the gene that codes for $\alpha$-L-iduronidase (pIDUA). ${ }^{6} \mathrm{~A}$ deficiency of this enzyme results in the lysosomal storage of the glycosaminoglycans, thereby causing the lysosomal storage disorder mucopolysaccharidosis type I (MPS I). The overall results showed that intravenous administration of pIDUA/ PEGylated cationic nanoemulsions (obtained by adsorption or encapsulation of preformed pIDUA-cationic lipid complexes) can significantly increase IDUA activity and expression in different organs, especially in the lungs and liver. ${ }^{7}$

Some well-documented studies have demonstrated that the single or multiple intravenous administration of cationic lipid-DNA complexes is often related to a dose- or timedependent effect, in terms of transfection efficiency and toxicity, especially in the liver and lungs. ${ }^{8-10}$ Similarly, the aim of this study was to evaluate the effect of the dose $(30$ and $60 \mu \mathrm{g})$ and time ( 2 or 7 days postinjection) on transfection efficiency of pIDUA/PEGylated cationic nanoemulsion complexes in a MPS I murine model. The gene expression and IDUA activity were evaluated after the intravenous administration of complexes obtained by the adsorption or encapsulation of preformed pIDUA-cationic lipid complexes into the oil phase of nanoemulsions. The potential toxicity of such complexes on main organs (ie, lungs, spleen, liver, and kidneys) was also evaluated.

\section{Materials and methods Materials}

Medium-chain triglycerides (MCTs), 1,2-dioleoylsn-glycero-3-phosphoethanolamine (DOPE), 1,2-dioleoyl$s n$-glycero-3-trimethylammonium propane (DOTAP), and 1,2-distearoyl-sn-glycero-3-phosphoethanolamine- $N$ (amino[polyethylene glycol]-2000) (DSPE-PEG) were purchased from Lipoid (Ludwigshafen, Germany). Glycerol and chloroform were obtained from Merck (Rio de Janeiro, Brazil). 4-Methylumbelliferylalpha-L-iduronide was purchased from Glycosynth (Warrington, UK), and TRIzol ${ }^{\circledR}$ Reagent was purchased from Thermo Fisher Scientific (Waltham, MA, USA). Platinum SYBR Green qPCR SuperMix-UDG kit was obtained from Thermo Fisher Scientific, and High-Capacity cDNA Reverse Transcription Kit was purchased from Thermo Fisher Scientific. All other chemicals were of analytical grades.

\section{Preparation of PEGylated cationic nanoemulsions}

Blank formulations were composed of $1.6 \%(\mathrm{w} / \mathrm{w}) \mathrm{MCT}$, 0.364\% (w/w) DOPE, 0.036\% (w/w) DSPE-PEG, 0.028\% DOTAP, $2.25 \%(w / w)$ glycerol, and Milli- ${ }^{\circledR}$ water up to $100 \%$ (PEGylated nanoemulsion [NEP]). The lipids were dissolved in chloroform and evaporated under reduced pressure $\left(50^{\circ} \mathrm{C}\right)$. The lipid film was hydrated with the water phase containing glycerol, vortexed for $3 \mathrm{~min}$, and left overnight. Next day, the formulations were vortexed for another $2 \mathrm{~min}$ and sonicated for $15 \mathrm{~min}$ at $37^{\circ} \mathrm{C}$. Finally, the emulsions were passed through high-pressure homogenization equipment at 10,000 psi for 10 cycles.

\section{Preparation of pIDUA/PEGylated cationic nanoemulsion complexes}

The plasmid pIDUA containing the human IDUA cDNA under the control of pCMV promoter was associated with nanoemulsions either by adsorption $\left(\mathrm{NEP} / \mathrm{pIDUA}_{\mathrm{A}}\right.$ ) on NEP or by incorporation of hydrophobic pIDUA-DOTAP complex into formulations during the nanoemulsion preparation $\left(\mathrm{NEP} / \mathrm{pIDUA} \mathrm{E}_{\mathrm{E}}\right)$. For the adsorption of pIDUA, a solution of pIDUA was added to nanoemulsions at room temperature and left for $30 \mathrm{~min}$. For the encapsulation of pIDUA, the hydrophobic pIDUA/DOTAP complex (prepared as previously described in detail by Fraga et $\mathrm{al}^{7}$ ) was added into the lipid mixture during nanoemulsion preparation followed by the high-pressure homogenization procedure. NEP/pIDUA and NEP/pIDUA E $_{\mathrm{E}}$ were prepared at $+4 /-$ charge ratio (charge ratio of cationic lipid/DNA phosphate groups).

\section{Physicochemical characterization}

The droplet size, polydispersity index, and $\zeta$-potential of blank PEGylated nanoemulsion and complexes were determined by photon correlation spectroscopy (PCS) at $90^{\circ}$ and electrophoretic mobility (3000HS Zetasizer). The samples were adequately diluted and analyzed just after preparation and after 2 months of storage at $4^{\circ} \mathrm{C}$.

\section{In vivo experiments}

Experiments were performed as previously described by Fraga et al. ${ }^{6,7}$ Briefly, four groups of mice (4-6 months) received $200 \mu \mathrm{L}$ of complexes containing 30 or $60 \mu \mathrm{g}$ of pIDUA obtained by adsorption (NEP/pIDUA $\mathrm{A}_{\mathrm{A}} \mathrm{n}=3$ /group) or encapsulation (NEP/pIDUA $\mathrm{E}_{\mathrm{E}}, \mathrm{n}=3$ /group) through intravenous injection in the tail vein. We compared these groups with nontreated MPS I mice of same age (MPS I, $\mathrm{n}=5$ ). Animals were euthanized $2(60 \mu \mathrm{g})$ or 7 days (30 and $60 \mu \mathrm{g})$ after injection by cervical dislocation under anesthesia. Liver, lungs, kidneys, and spleen were isolated, and a piece of each was flash frozen in liquid nitrogen for biochemical analysis and mRNA extraction, with the rest used for histology. Before euthanizing the mice, serum was collected by retroorbital puncture. Data of mice receiving $30 \mu \mathrm{g}$ and euthanized 2 days postinjection were compared with our previous work, which followed the same protocol. ${ }^{7}$ 
Gene expression assay to evaluate IDUA transcription levels from the plasmid was performed by real-time polymerase chain reaction with Platinum SYBR Green qPCR SuperMix-UDG kit. Approximately $30 \mathrm{mg}$ of flash frozen tissues were used for mRNA extraction with TRIzol ${ }^{\circledR}$ Reagent, and the conversion of RNA to cDNA was performed using High-Capacity cDNA Reverse Transcription Kit. GAPDH was used as a reference gene to account for any variance in the quality of mRNA and the amount of input cDNA. The following primers were used: forward IDUA 5'-CACTGGCTGCTGGA GCTT-3', reverse IDUA 5'-GCTCAAACCCTGGGAGGA-3'; forward GAPDH 5'-CCCATCACCATCTTCCAGG-3', reverse GAPDH 5'-CATATTTGGCAGCTTTCTCC-3'. The polymerase chain reaction was carried out according to the manufacturer's instructions, and the results were presented as described by Livak and Schmittgen. ${ }^{11}$

For IDUA activity measurements, $\sim 30 \mathrm{mg}$ of tissues were homogenized in distilled water. IDUA activity assay was performed incubating protein extracts with fluorescent substrate 4-methylumbelliferyl $\alpha$-L-iduronide at $37^{\circ} \mathrm{C}$ for $1 \mathrm{~h}$ in sodium formate buffer ( $\mathrm{pH} 2.8$ ) with some modifications. ${ }^{12}$ Fluorescence was measured at $365 \mathrm{~nm}$ (excitation) and $450 \mathrm{~nm}$ (emission) using a fluorescence spectrophotometer, SpectraMax M2. Results are expressed as nanomole per hour per milligram of protein. Protein content was measured using the method described by Lowry et al. ${ }^{13}$

\section{Histological analysis}

Tissues were fixed in buffered formalin and processed and embedded in paraffin wax. Thin cross-sections were submitted to routine histological processing, stained with hematoxylineosin (H-E), and analyzed for signs of toxicity.

\section{Immunohistochemistry}

Immunohistochemistry for CD68 was performed in kidneys, liver, spleen, and lungs samples using specific antibody (mouse polyclonal anti-CD68; Abcam, Cambridge, UK). A horseradish peroxidase-conjugated antirabbit IgG was used as secondary antibody. The slides were analyzed by a researcher blinded to the groups. Cells positively stained for CD68 were analyzed in 3-5 fields per slide, with a 200× magnification. Results are expressed as the number of CD68positive cells per square millimeter of tissue sections.

\section{Ethics}

All experiments were approved by the ethics committee of our institution (Research Ethics Committee of Hospital de Clínicas de Porto Alegre - permit numbers 09-0334 and 12-0477). Animal procedures were carried out in accordance with the recommendations in the Guide for the Care and Use of Laboratory Animals of the National Institutes of Health, monitored by our veterinarian, and designed to minimize animal suffering.

\section{Statistics}

Results are expressed as the mean \pm standard error of the mean (SEM). Differences were considered to be significant at $P<0.05$. Analysis of the data was performed using Student's $t$-test on IBM $^{\circledR}$ SPSS $^{\circledR}$ Statistics, v 18.0 (Quarry Bay, Hong Kong).

\section{Results \\ Physicochemical characterization}

Table 1 exhibits the droplet size, polydispersity index, and $\zeta$-potential of NEP/pIDUA ${ }_{\mathrm{A}}$ and NEP/pIDUA ${ }_{\mathrm{E}}$.

As can be seen, the high-pressure homogenization procedure yielded monodisperse nanoemulsions (polydispersity index $<0.2$ ), exhibiting a mean droplet size of $\sim 200-300 \mathrm{~nm}$. Regardless of the method of incorporation (NEP/pIDUA or NEP/pIDUA ${ }_{\mathrm{E}}$ ), an inversion of $\zeta$-potential was detected from +30 to $\sim-10 \mathrm{mV}$. Such a result suggests that, at least partially, a part of the plasmid pIDUA is located at the oil/water interface of nanoemulsions.

\section{In vivo experiments}

Figure 1 exhibits the relative expression of IDUA by quantitative real-time polymerase chain reaction in different organs (lungs, spleen, liver, and kidneys) of MPS I mice. The Ct value of nontreated MPS I mice for IDUA expression was used to calibrate relative expression calculations (varied from 38 to 40). IDUA was expressed in main organs of treated MPS I mice. As shown in Figure 1, IDUA expression was higher in the lungs when the dose was increased from 30 to $60 \mu \mathrm{g}$ and it was maintained after 7 days postinjection in animals

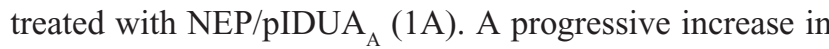
$I D U A$ expression was observed with an increase in the dose and time of transfection for mice treated with both complexes $\left(\mathrm{NEP} / \mathrm{pIDUA} \mathrm{A}_{\mathrm{A}}\right.$ and NEP/pIDUA $\mathrm{E}_{\mathrm{E}}$ ), especially in the liver and kidneys. A higher IDUA expression in the spleen was detected in animals treated with 30 and $60 \mu \mathrm{g}$ of pIDUA 7 days after the injection, regardless of the complex administered.

Table I Physicochemical properties of blank nanoemulsion and complexes

\begin{tabular}{|c|c|c|c|}
\hline Code & Droplet size $(\mathrm{nm})$ & PI & $\zeta$-potential $(\mathrm{mV})$ \\
\hline NEP & $225.8 \pm 1.5$ & $0.10 \pm 0.06$ & $+\mid 4 . I \pm I .4$ \\
\hline NEP/pIDUA $A_{A}$ & $263.9 \pm 20.2$ & $0.05 \pm 0.03$ & $-9.8 \pm 6.7$ \\
\hline NEP/PIDUA ${ }_{E}$ & $242.5 \pm 2.1$ & $0.12 \pm 0.04$ & $-8.4 \pm 1.1$ \\
\hline
\end{tabular}

Note: Results represent the mean \pm standard deviation of three experiments. Abbreviations: NEP, PEGylated nanoemulsion; Pl, polydispersity index. 
A

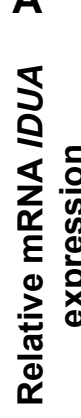

10,000

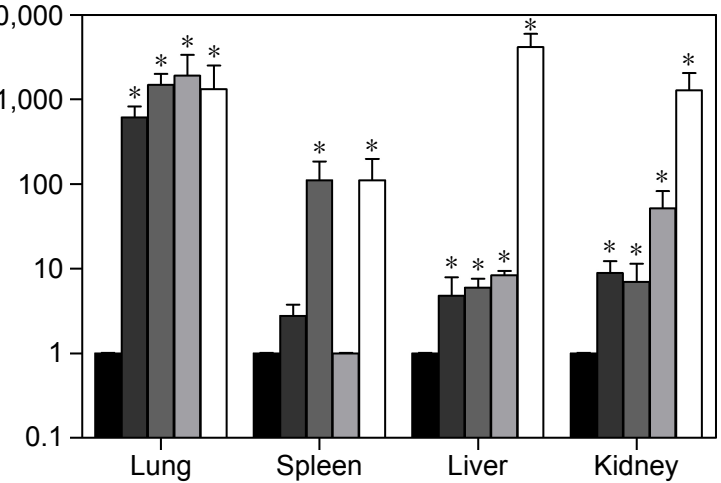

B

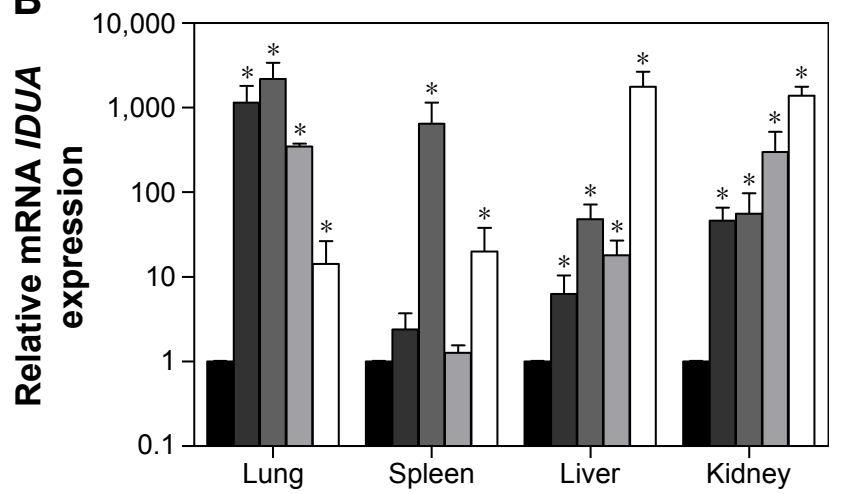

MPS I

$30 \mu \mathrm{g}-2$ days $^{\#}$

$30 \mu \mathrm{g}-7$ days

$60 \mu \mathrm{g}-2$ days

$60 \mu \mathrm{g}-7$ days

Figure I Relative expression of IDUA by real-time RT-qPCR in different organs of MPS I mice treated with NEP/PIDUA $($ A) and NEP/pIDUA $($ B).

Notes: Mice were treated with $30 \mu \mathrm{g}$ of pIDUA (dark gray bars) or $60 \mu \mathrm{g}$ of pIDUA (light gray bars) and euthanized 2 days after intravenous injection or $30 \mu \mathrm{g}$ of pIDUA (medium gray bars) or $60 \mu \mathrm{g}$ of pIDUA (white bars) and euthanized 7 days after intravenous injection. Nontreated MPS I mice were used as control (black bars). Expression ratios are relative to GAPDH endogenous control. Values represent the mean \pm standard error of the mean and are presented in log scale. *Difference between treated and nontreated MPS I mice (Student's $t$-test, $P<0.05$ ). "Data from Fraga et al. ${ }^{7}$

Abbreviations: MPS I, mucopolysaccharidosis type I; RT-qPCR, quantitative real-time polymerase chain reaction.

In similar experimental conditions, IDUA activity was measured in the main organs and compared with nontreated MPS I mice, which were used as negative controls (Table 2). The results showed an increased IDUA activity in the lungs after the injection of $30 \mu \mathrm{g}$ after 2 days postadministration $(1.36 \mathrm{nmol} / \mathrm{h} / \mathrm{mg}$ of protein) for NEP/pIDUA .

Regardless of the complex administered, a significant increase in IDUA activity $(P<0.05)$ was detected in lungs and liver compared with nontreated MPS I when a dose of $60 \mu \mathrm{g}$ was administered and IDUA activity was measured

Table 2 IDUA activity in different organs of MPS I mice treated with NEP/PIDUA $A_{A}$ or NEP/PIDUA

\begin{tabular}{|c|c|c|c|c|}
\hline \multirow[t]{2}{*}{ Treatment } & \multicolumn{4}{|c|}{ IDUA activity (nmol/h/mg of protein) } \\
\hline & Lung & Spleen & Liver & Kidney \\
\hline \multicolumn{5}{|l|}{$30 \mu g / 2$ days $^{\mathrm{a}}$} \\
\hline NEP/pIDUA ${ }_{A}$ & $1.36 \pm 0.13 *$ & $0.10 \pm 0.01$ & $0.73 \pm 0.03 *$ & $0.59 \pm 0.10^{*}$ \\
\hline NEP/pIDUA & $0.39 \pm 0.07$ & $0.17 \pm 0.02 *$ & $1.10 \pm 0.03 *$ & $0.59 \pm 0.02 *$ \\
\hline \multicolumn{5}{|l|}{$30 \mu \mathrm{g} / 7$ days } \\
\hline $\mathrm{NEP} / \mathrm{pIDUA} \mathrm{A}_{\mathrm{A}}$ & $0.24 \pm 0.02$ & $0.10 \pm 0.02$ & $0.52 \pm 0.07$ & $0.18 \pm 0.04$ \\
\hline NEP/PIDUA & $0.27 \pm 0.04$ & $0.09 \pm 0.03$ & $0.67 \pm 0.09 *$ & $0.18 \pm 0.01$ \\
\hline \multicolumn{5}{|l|}{$60 \mu \mathrm{g} / 2$ days } \\
\hline $\mathrm{NEP} / \mathrm{pIDUA} \mathrm{A}_{\mathrm{A}}$ & $0.28 \pm 0.03$ & $0.14 \pm 0.01$ & $0.48 \pm 0.06$ & $0.24 \pm 0.03$ \\
\hline NEP/PIDUA & $0.27 \pm 0.05$ & $0.18 \pm 0.05$ & $0.6 I \pm 0.03 *$ & $0.28 \pm 0.03$ \\
\hline \multicolumn{5}{|l|}{$60 \mu g / 7$ days } \\
\hline $\mathrm{NEP} / \mathrm{pIDUA} \mathrm{A}_{\mathrm{A}}$ & $0.4 I \pm 0.04 *$ & $0.12 \pm 0.05$ & $0.55 \pm 0.05^{*}$ & $0.29 \pm 0.10$ \\
\hline NEP/PIDUA & $0.42 \pm 0.06 *$ & $0.03 \pm 0.008$ & $0.54 \pm 0.04 *$ & $0.23 \pm 0.03$ \\
\hline MPS I (nontreated) & $0.26 \pm 0.02$ & $0.10 \pm 0.01$ & $0.35 \pm 0.06$ & $0.25 \pm 0.03$ \\
\hline
\end{tabular}

Notes: Results represent the mean \pm standard error of the mean. *Difference between

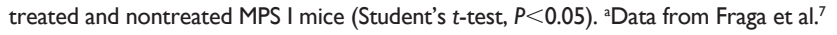
Abbreviations: MPS I, mucopolysaccharidosis type I; NEP, PEGylated nanoemulsion.
7 days postadministration. Furthermore, significant IDUA activity $(P<0.05)$ was present in the liver in all treatment conditions in accordance with the increase in IDUA expression in this organ.

\section{Histological and immunohistochemistry analysis}

Finally, the potential toxicity of pIDUA/PEGylated cationic nanoemulsion complexes was evaluated in dissected major organs, such as liver, lungs, kidneys, and spleen, 7 days postadministration of $60 \mu \mathrm{g}$ of pIDUA (Figures 2 and 3). Tissue sections of major organs showed no presence of cell necrosis, inflammatory infiltrate, or an increase in apoptosis. Only mild hydropic degeneration was detected in the liver when compared with nontreated MPS I mice, regardless of the type of complex (NEP/pIDUA ${ }_{A}$ or NEP/-pIDUA ${ }_{E}$ ) that was administered intravenously (Figure 2). Immunohistochemistry for CD68, a macrophage lineage cell marker, showed no quantitative difference $(P>0.05)$ in the number of these cells in treated and nontreated animals, indicating the absence of inflammatory reaction caused by the treatment (Figure 3).

\section{Discussion}

We have recently described an increase in IDUA activity and expression in different organs after the intravenous administration of pIDUA/PEGylated cationic nanoemulsion complexes. ${ }^{7}$ However, in this study, our aim was to investigate the effect of dose and time on these parameters. 

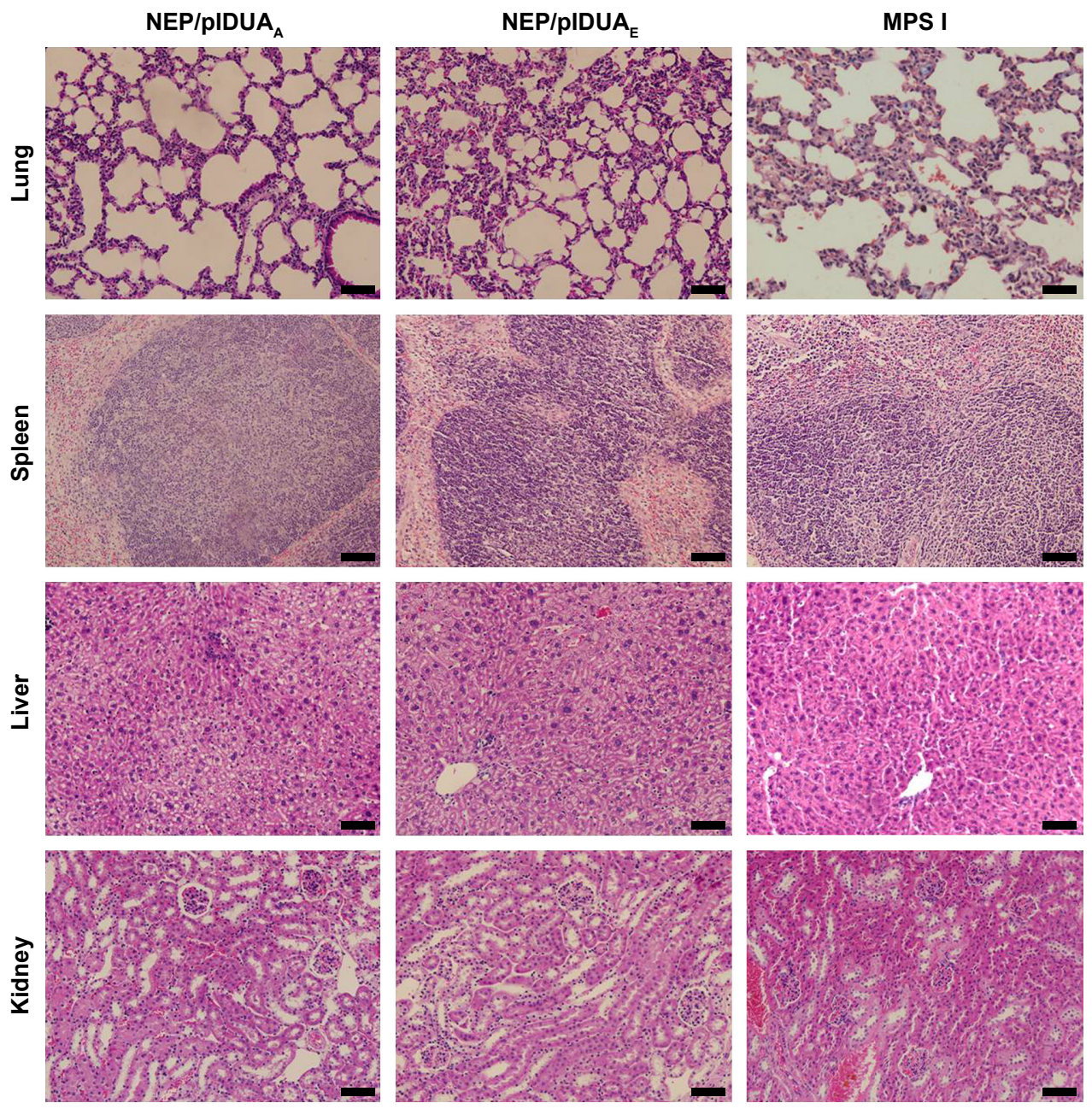

Figure 2 Representative histological sections stained with $\mathrm{H}-\mathrm{E}$ of different organs of treated groups (NEP/pIDUA $\mathrm{A}_{\mathrm{A}}$ and NEP/pIDUA $\mathrm{E}_{\mathrm{E}}$ ) and of negative control (MPS I). Notes: Scale bars in figure represent $100 \mu \mathrm{m}$. Magnification $\times 200$.

Abbreviations: H-E, hematoxylin-eosin; MPS I, mucopolysaccharidosis type I; NEP, PEGylated nanoemulsion.

Since transfection efficiency is a measure prone to many variable factors, including those related to the properties of vectors, in this study, we evaluated the physicochemical properties of complexes.

The results of physicochemical properties are in agreement with those observed in our previous studies. ${ }^{6,7}$ The main physicochemical properties of complexes remained similar after 60 days of storage at $4^{\circ} \mathrm{C}$. This could be related to the stability provided by the PEG moiety of DSPE-PEG, since its steric hindrance may prevent the aggregation and neutralization of positive charge of pIDUA/PEGylated cationic nanoemulsion complexes. ${ }^{14}$

To assess the carrier's ability to efficiently transfect cells in vivo, the relative quantification of IDUA and GAPDH gene expressions in the organs of animals in the treatment groups was performed using cDNA samples from different tissues. Mice were treated with NEP/pIDUA ${ }_{\mathrm{A}}$ or NEP/
pIDUA $_{\mathrm{E}}$ at a final dose of 30 or $60 \mu \mathrm{g}$ and euthanized 2 or 7 days postinjection. Animals treated with $30 \mu \mathrm{g}$ of pIDUA and euthanized 2 days after the injection were from our previous work, performed under the same conditions, ${ }^{7}$ and were included in this study for comparison purposes. That allowed us to show a progressive increase in IDUA expression with an increase in the dose and time of transfection, for mice treated with both complexes (NEP/pIDUA $A_{A}$ and NEP/ pIDUA $_{E}$ ). Information about the effect of time and dose can vary greatly in the literature and depends on the model used. Our results follow in line with those reported by Kim et al ${ }^{8}$ and Yoo et al, ${ }^{10}$ in which an increase in pDNA dose leads to higher gene expression, showing that an effect of dose and time seems to occur.

We have previously speculated that the increased IDUA activity in the lungs 2 days after the administration of $30 \mu \mathrm{g}$ of NEP/pIDUA $A_{A}$ results from a possible lung embolization 
A
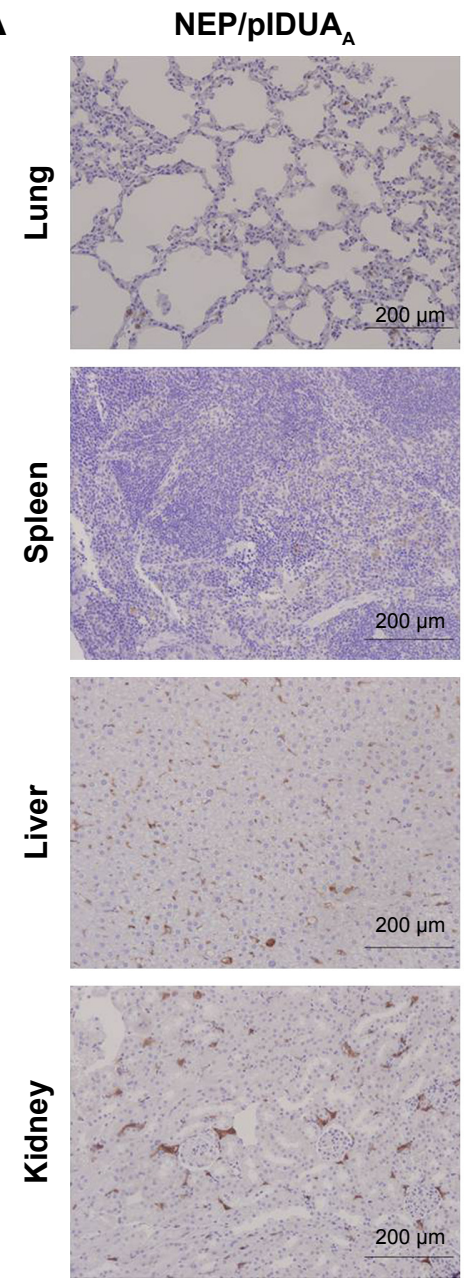

B

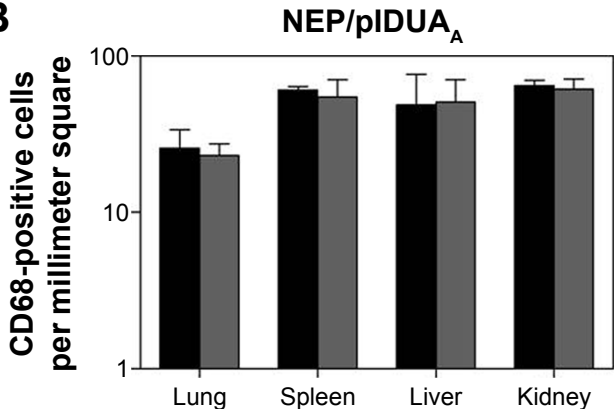

NEP/pIDUA
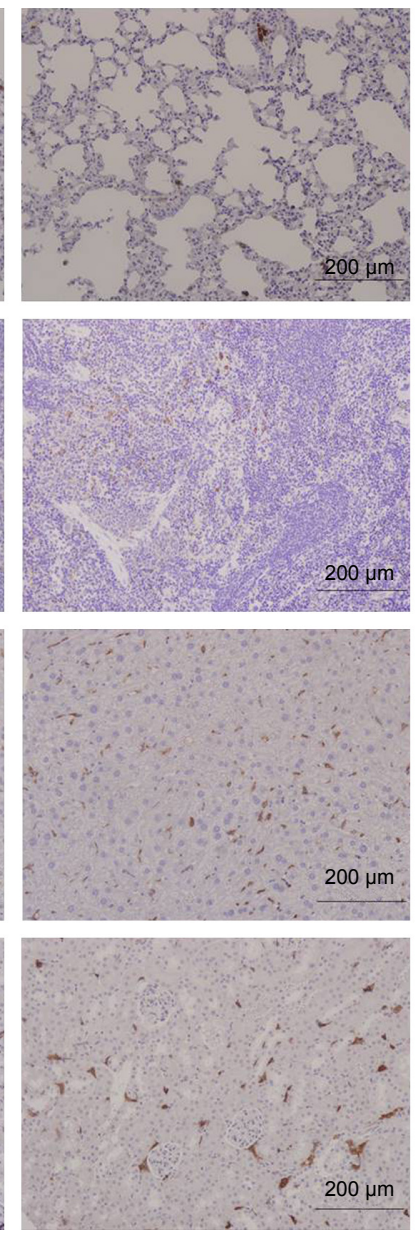

MPS I
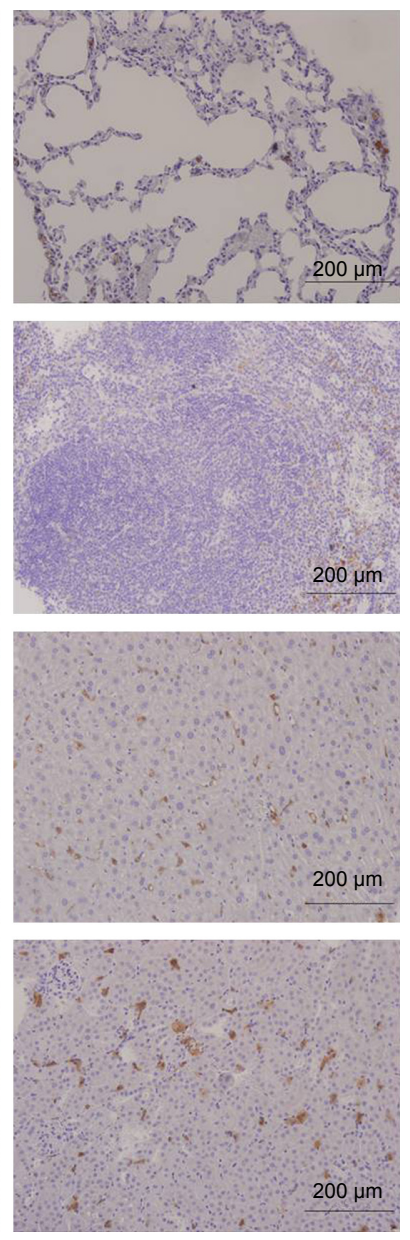

NEP/PIDUA

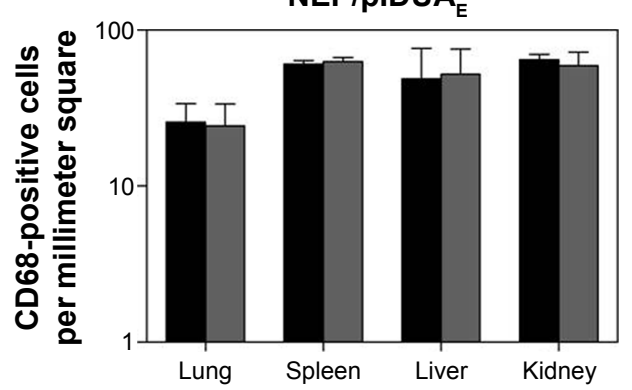

Figure 3 CD68 immunohistochemistry.

Notes: (A) Representative sections of different organs of treated groups (NEP/pIDUA and NEP/pIDUA $A_{E}$ ) and negative control (MPS I). Magnification $\times 200$. (B) Quantification of CD68-positive cells per millimeter square of tissue. Treated mice are in dark gray bars, and nontreated MPS I mice are in black bars. Values represent the mean \pm standard error of the mean.

Abbreviations: MPS I, mucopolysaccharidosis type I; NEP, PEGylated nanoemulsion.

of this complex that was not observed when pIDUA was encapsulated (NEP/pIDUA $\left.A_{E}\right){ }^{?}$

Although previous studies have shown that a dose of $60 \mu \mathrm{g}$ of pDNA in a similar formulation using DOTAP can cause a widespread toxicity and architectural damage ${ }^{9}$ and these authors also used a charge ratio of $+4 /-$, our histological and immunohistochemistry evaluations did not show any signs of toxicity of the evaluated complexes on the MPS I mice model at this plasmid dose; maybe this difference was due to the use of DSPE-PEG in our formulation.

\section{Conclusion}

The set of results demonstrates that dose and time might have an effect on transfection efficiency to a different extent in 
each organ. In the lungs, the expression and activity were influenced by the mode by which pIDUA was associated with PEGylated cationic nanoemulsions. A significantly higher IDUA gene expression and IDUA activity were detected in the liver 7 days postadministration of the highest pIDUA dose. In these conditions, there was no evidence of a deleterious effect of the complexes on different organs of MPS I mice.

\section{Acknowledgments}

This study was supported by the National Council for Scientific and Technological Development (grant agreement number 478426/2011-9) and by the Research Incentive Fund of HCPA (FIPE/HCPA). This article is a part of Fraga's doctoral thesis, which was granted with honorable mention by Coordenação de Aperfeiçoamento de Pessoal de Nível Superior (CAPES).

\section{Disclosure}

The authors report no conflicts of interest in this work.

\section{References}

1. Cotrim AP, Baum BJ. Gene therapy: some history applications, problems, and prospects. Toxicol Pathol. 2008;36(1):97-103.

2. Kawakami S, Higuchi Y, Hashida M. Nonviral approaches for targeted delivery of plasmid DNA and oligonucleotide. J Pharm Sci. 2008; 97(2):726-745.

3. Nam HY, Park JH, Kim K, Kwon IC, Jeong SY. Lipid-based emulsion system as non-viral gene carriers. Arch Pharm Res. 2009;32(5):639-646.
4. Karmali PP, Chaudhuri A. Cationic liposomes as non-viral carriers of gene medicines: resolved issues, open questions, and future promises. Med Res Rev. 2007;27(5):696-722.

5. Verissimo LM, Lima LF, Egito LC, De Oliveira AG, Do Egito ES Pharmaceutical emulsions: a new approach for gene therapy. J Drug Target. 2010;18(5):333-342.

6. Fraga M, de Carvalho TG, Diel Dda S, Kretzmann Filho NA, Teixeira HF, Matte U. Cationic nanoemulsions as a gene delivery system: proof of concept in the mucopolysaccharidosis I murine model. J Nanosci Nanotechnol. 2015;15(1):810-816.

7. Fraga M, Bruxel F, Diel D, et al. PEGylated cationic nanoemulsions can efficiently bind and transfect pIDUA in a mucopolysaccharidosis type I murine model. J Control Release. 2015;209:37-46.

8. Kim TW, Chung H, Kwon IC, Sung HC, Shin BC, Jeong SY. Airway gene transfer using cationic emulsion as a mucosal gene carrier. $J$ Gene Med. 2005;7(6):749-758.

9. Kwon SM, Nam HY, Nam T, et al. In vivo time-dependent gene expression of cationic lipid-based emulsion as a stable and biocompatible non-viral gene carrier. $J$ Control Release. 2008;128(1):89-97.

10. Yoo HS, Mazda O, Lee HY, et al. In vivo gene therapy of type I diabetic mellitus using a cationic emulsion containing an Epstein Barr Virus (EBV) based plasmid vector. J Control Release. 2006; 112(1):139-144.

11. Livak KJ, Schmittgen TD. Analysis of relative gene expression data using real-time quantitative PCR and the 2(-Delta Delta C(T)) Method. Methods. 2001;25(4):402-408.

12. Baldo G, Mayer FQ, Burin M, Carrillo-Farga J, Matte U, GiuglianI R. Recombinant encapsulated cells overexpressing alpha-L-iduronidase correct enzyme deficiency in human mucopolysaccharidosis type I cells. Cells Tissues Organs. 2012;195(4):323-329.

13. Lowry OH, Rosebrough NJ, Farr AL, Randall RJ. Protein measurement with the Folin phenol reagent. J Biol Chem. 1951;193(1):265-275.

14. Chesnoy S, Durand D, Doucet J, Stolz DB, Huang L. Improved DNA/ emulsion complex stabilized by poly(ethylene glycol) conjugated phospholipid. Pharm Res. 2001;18(10):1480-1484.
International Journal of Nanomedicine

\section{Publish your work in this journal}

The International Journal of Nanomedicine is an international, peerreviewed journal focusing on the application of nanotechnology in diagnostics, therapeutics, and drug delivery systems throughout the biomedical field. This journal is indexed on PubMed Central, MedLine, CAS, SciSearch ${ }^{\circledR}$, Current Contents ${ }^{\circledR} /$ Clinical Medicine,

\section{Dovepress}

Journal Citation Reports/Science Edition, EMBase, Scopus and the Elsevier Bibliographic databases. The manuscript management system is completely online and includes a very quick and fair peer-review system, which is all easy to use. Visit http://www.dovepress.com/ testimonials.php to read real quotes from published authors. 